\title{
Global health and natural disaster alerts: preparing mobile phones to endure the unthinkable
}

\author{
Wladimir J Alonso ${ }^{1,2^{*}}$, Cynthia Schuck-Paim² and Ghassem R Asrar ${ }^{3}$
}

\begin{abstract}
Despite the increasingly positive role of portable communication technologies for socioeconomic development and their growing use in global health and other emergency contexts, several challenges still hinder exploring the full potential of mobile phones as effective mitigation tools in natural disasters, public health emergencies and in the aftermath of extreme disruptive events. Mobile devices are designed and advertised to withstand predominantly the demands of normal daily situations, being fraught with fragilities that limit their utility for effective communication and coordination of help in emergency situations. We discuss ways to overcome some of these limitations in the future by the incorporation of features to increase their resilience and effectiveness as aid tools at relatively low cost. Improvements in autonomous energy generation and use, based on existing and rapidly emerging technologies, as well as further improvements in physical durability and off-line operability are encouraged. We also identify the possibility to combine capabilities from other devices, such as space-based telecommunication systems and traditional two-way radios, to enhance the utility of mobile devices for these applications. The solutions we propose can help millions of citizens around the world to manage the risks and impacts of natural and health-related hazards. They should also promote further resilience to avoiding and recovering from such events, especially in vulnerable regions with limited infrastructure.
\end{abstract}

Keywords: Disaster; Emergency; Mobile; Preparedness; Communication; Relief

\section{Report}

We just celebrated the 40th anniversary of the first call made from a mobile phone (BBC 2013). Since then, an extraordinary technological revolution has been unleashed, enabling three-quarters of the world population (and much of the developing world) to have access to this powerful communication device at all times (The World Bank 2012). Nowadays, more people in the world have access to mobiles than to basic sanitation. Almost everywhere, individuals are in constant contact with peers, family, business partners, service providers and an ever growing number of information sources. The rippling effects brought about by these ubiquitous communication opportunities on the living standards of populations include the creation of job

\footnotetext{
* Correspondence: wladimir.alonso@nih.gov

${ }^{1}$ Fogarty International Center, National Institutes of Health (NIH), 16 Center Drive, Building 16, 20892 Bethesda, MD, USA

${ }^{2}$ Origem Scientifica, Sao Paulo, Brazil

Full list of author information is available at the end of the article
}

opportunities, the promotion of political transparency, the early containment of epidemic outbreaks, the early warning of hazards and the possibility to scale up global health systems (The World Bank 2012; The Economist 2009a; The Economist 2009b; Quadir 2005; Lester \& Karanja 2008; BBC Media Action 2012; The Economist 2007).

Mobile phones have also played an increasingly positive role as disaster relief tools. Since the year 2000, natural disasters and extreme weather events have caused over one million deaths and directly affected more than 2 billion people (Guha-Sapir et al. 2013). In addition to mass injury and death, common features of such disasters include damage to infrastructure, difficult access to basic goods, overburden of emergency and medical services and frequent isolation of victims. Although we currently count on sophisticated forecast and response systems (such as early assessment of hurricane paths or of the likelihood of a new disease spreading), new vulnerabilities are also present due to the increasing complexity of infrastructures and rapid 
expansion of megacities (especially in regions that are geologically and/or meteorologically vulnerable), interdependency of technologies and their massive use by growing populations (Kenett \& Portugali 2012). In such contexts, the use of mobile phones can be critical, particularly in light of the likely collapse of terrestrial telecommunication infrastructures following a disaster (Patricelli et al. 2009; Townsend \& Moss 2005).

However, several challenges still constrain the greater potential that mobile phones offer as effective mitigation tools in the aftermath of disasters and in other emergencies. For example, during earthquakes, hurricanes, floods, pandemics and other severe disease outbreaks, economic, societal and personal infrastructures are severely affected and governmental capabilities become quickly saturated due to the sheer demand for assistance. Although in such cases timely communication, information gathering and coordination are crucial to assist those in need, the availability, proper functioning and supporting infrastructure of mobile technologies is still fraught with fragilities and limitations that prevent them from being fully effective (Patricelli et al. 2009; Townsend \& Moss 2005; West \& Valentini 2013; Guo \& Su 2012; Effros et al. 2010; The Telegraph 2011; Napolitano 2009; Xia 2011; Palen \& Liu 2007; Yang et al. 2009; Zook et al. 2010). Here we discuss ways forward to overcome these limitations, proposing the incorporation of features to increase their resilience and effectiveness as mitigation tools at relatively low cost. Some of the measures proposed are not tied to daunting technological demands, but simply require unlocking capabilities already available, and affordably. Although our focus is mainly on natural disasters and global health crises, the solutions we identify are also useful to manage a wide range of emergencies that routinely affect millions of people around the world, especially in vulnerable and highly populated regions.

\section{The potential of mobile phones as effective aid tools}

We consider two major mobile phone categories: cell phones and smartphones. In addition to voice communication and text messaging capabilities, cell phones can include features such as digital cameras and radio receivers. Smartphones share these features, but have also become powerful computing machines that can handle complex tasks and accommodate a wider array of human-centric sensor devices (Srivastava et al. 2012). Those capabilities are increasingly explored through the development of software applications across a vast array of themes, including those useful for emergency preparedness and response (West \& Valentini 2013). However, cell phones are cheaper, have more energy autonomy, and are still the device of choice among developing nations and regions, and more vulnerable populations (like the elderly), so they should not be overlooked for planning and preparedness purposes. Moreover, while some smartphone apps are also useful off- line, they still require access to a data network to be installed or run, hindering their usefulness when data transfer is not possible. Other communication devices such as tablets, computers and land-lines share several of the capabilities mentioned. However, the ubiquity of mobile phones at all times makes them uniquely suited as a critical resource for assistance in unexpected and disruptive scenarios, hence we will focus mainly on these devices.

We first briefly consider major fronts where current capacities and improvements in mobile phones can harness the power of rapidly developing technologies to serve society, especially in the fields of human health, environment and humanitarian assistance, alerts and emergencies.

\section{Distress calls and establishing first line of contact}

Mobile phones already represent the main means to establish the first line of contact to ask (or offer) help, and to obtain information through which help can be offered and achieved, and about the situation of relatives and friends. This is, by far, the most important and useful service that mobile devices offer under dire scenarios. Accordingly, most of the suggestions we will discuss are aimed to secure such capabilities under a wide range of stressing conditions.

\section{Receiving critical information}

When other means of communication (TV, radio, computers) are not accessible (e.g., out of reach or impaired), mobile devices can be the only source of information on evacuation plans and procedures, on the availability of shelters and other facilities, services and resources, weather forecasts, survival recommendations and other arguably life saving information.

\section{Disseminating data and information to aid agencies}

During earthquakes, hurricanes, floods, pandemics and other severe disease outbreaks, economic, societal and personal infrastructures are severely affected and governmental capabilities become quickly saturated due to the sheer demand for assistance. In such contexts timely communication, information gathering and coordination are crucial to assist those in need. Mobile phones can provide information and coordination of help to victims and vulnerable individuals, enable rapid data collection (Lurie et al. 2013) and even track in real-time population movements in the context of relief efforts (Bengtsson et al. 2011).

\section{Other applications}

Other potential uses may range from those of psychological nature (as they can comfort and even entertain victims, helping lower panic and distress levels) to support of onsite data gathering and parallel computing processing just to name a few. For example, crowd sourcing to collect critically important information about a given situation or on a sustained basis to develop long-term records about 
environmental, demographic and health factors is also being considered by a wide range of organizations at the national and international levels.

These applications are intended to serve only as examples of practical and innovative ways that mobile devices can be used in service to society, and should not be viewed as an exhaustive list. In the next section we identify some of the current fragilities of mobile devices that limit their use for such conditions and applications, and propose the use of existing and emerging technologies to make them more resilient and useful in the future.

\section{Existing fragilities and proposed solutions}

Critical capabilities are needed to ensure that mobile phones can serve at least the most essential roles previously discussed. Among obvious features, physical durability, energy autonomy, and network availability are most essential. But other features such as redundancy of frequency channels for communication are also important to turn these devices into effective aid tools in emergencies. We highlight current capabilities and limitations, and propose solutions based on existing and emerging technologies.

\section{Off-line operability}

Both communications and access to remotely stored information are interrupted when the network structure of mobile operators is damaged. In such cases, off-line features can provide assistance.

One such important off-line feature has unnecessarily vanished, or is deactivated, from many modern mobile phones: the radio receptor. Although news, music and information can now be streamed directly from data networks through smartphone apps, direct access to radio stations should not be considered redundant. Datastreaming requires that several antennae and terrestrial structures provided by mobile operators function properly, whereas the signal from each radio station is broadcasted independently. Only one radio station suffices for the mobile user to make use of it. Radio stations have been shown to be important in crises (Xia 2011; Covello \& Hyer 2007; Baze 2012; National Association Broadcasters (NAB) 2013), and when combined with social media (if accessible) their impact can be largely amplified (BBC Media Action 2012). The National Association of Broadcasters states that the top 10 phones in the marketplace already include radio chips that are simply not activated (Murray 2010). Given the ease of reactivating radio receptors into mobile devices, their inclusion or activation in all future devices would be highly advisable. Moreover, because the costs of keeping an already existing feature would be likely very low, educating consumers about its effectiveness in emergency and disruptive scenarios could also contribute to a greater market penetration of these devices.
Another off-line feature that can be of great value in a disaster is geolocation capability. GPS access signals directly from satellites, hence does not necessarily depend on internet and data services. However, maps currently in use often access data in real time from on-line sources, rendering the information provided by the GPS nearly useless if map data cannot be downloaded. Users should thus always have a back-up map of their homes or destination and surroundings. Some smartphone apps that can work off-line that do not rely on or require a data network to run can be also useful (West \& Valentini 2013).

\section{Energy autonomy}

The short battery life of most smartphones (Neild 2013) is a major limitation in emergency situations. Electrical grids can be severely damaged following a disaster, and although a few hours of autonomy may suffice for emitting the first distress calls, most emergencies last much longer. In lifethreatening circumstances (such as when victims are under the rubble) the interruption of service can be fatal or cause major damage (Daily Mail Reporter 2011).

Cell phones often have more autonomy, usually several days, as they lack the power-hungry screens and processors of smartphones. Indeed, they have already proven useful during power outages or breakdowns in developing countries (Bengtsson et al. 2011), and are a suggested back-up means of communication even for smartphone users (Stout \& Neild 2013). While this may be wise advice, it is unlikely that most smartphone users will constantly carry two devices.

In addition to improving energy autonomy, creative methods of charging mobile phones should be considered. Solar cells, physical motion chargers, micro-fuel cells and external batteries can be purchased separately to provide greater autonomy. Interestingly, solar cells based on nano- and thin-film technologies that are embedded in or integrated in mobile phones are promising technologies. For example, solar powered phones were distributed in the aftermath of the catastrophic earthquake in the Chinese province of Sichuan during efforts to recover mobile communication (Guo \& Su 2012; Yang et al. 2009). Some of those solutions could be integrated into future phones.

\section{Alternative channels of communication}

Where fiber optic cables and electricity are still operational (no doubt an optimistic scenario in a major catastrophe) the Internet or other packet-switched networks could still be used (Murray 2010). But if mobile phone networks are down or overloaded, alternative channels of communication that are independent of external infrastructure (towers, cables) should be considered. One example is the critical role played by amateur and FRS/GMRS radios (Baze 2012). Ad-hoc networks by which each mobile 
phone in range functions as a relay point for other mobile devices also represent a promising technological avenue (Effros et al. 2010; Australian Broadcast Corporation ABC 2010). Another possibility is the integration of two-way radio channels into mobile devices, opening opportunities for close range communication (Zhou et al. 2012). There are also existing satellite phones which do not depend on the terrestrial infrastructure (Baze 2012). Indeed, those were the only devices that could be operated by medical relief teams in the aftermath of the Great East Japan Earthquake in 2011 (Fuse 2011). The ability to access space-based telecommunication networks directly, and affordably, from mobile phones would greatly increase resilience to disasters.

\section{Physical durability}

Durability and ruggedness is not a common feature of most mobile phones. A quick glance at footages of natural disasters suggests that most currently available devices would likely become inoperable under the physical stress imposed during such events. In what is perhaps the early rise of a welcoming trend, some devices are under development with sturdier features such as shock resistance and water proofing (CNET 2013). The technology to improve the ruggedness of mobile phones, for example by using carbon fiber materials, is already available, and manufacturing costs do not seem to be a major barrier.

\section{Distress mode}

Individuals who need to let others know about their whereabouts could greatly benefit from the activation of a distress mode in their devices. While saving as much energy as possible (e.g. by turning off non-essential features), a distress mode could regularly send pulse signals, which could be composed of a sound, a flash, and a radio signal containing data with personal information of medical relevance and individual location. This feature could be based on existing Personal Locator Beacons, SPOT Personal Trackers and the Iridium satellite system (Baze 2012) and could be built based on Digital Distress Identifiers that are already used by medically impaired costumers and as personal emergency alerts in accidents, as well as personal, community, state and regional emergencies. Even if victims fell unconscious, this feature (which could be built-in to enable its activation manually, by a voice command or even remotely by another device using a secure protocol) would increase the possibilities of a successful rescue.

\section{Network resilience}

Although mobile phone networks are relatively resilient to external shocks, disasters can affect power supply, destroy towers, and cause complete loss of functionality (Townsend \& Moss 2005; West \& Valentini 2013;
Bengtsson et al. 2011; Bengtsson et al. 2011; Baze 2012). During the superstorm Sandy in 2012, which took place in one of the most developed and prepared places on Earth, mobile phone networks were frequently down (Allen 2012; The Economist 2012). Network data links should therefore be not only more resistant to damage, but also redundant, diversified and able to activate back-up systems when antennas and cables are damaged (Patricelli et al. 2009; Xia 2011; Fuse 2011). There is not much that consumers or manufacturers can do in this regard (other than promote redundancy by allowing mobile phones to use more than one network provider in the same device). Ultimately, the resilience of the communications network is a matter of national security. It is thus up to governments to detect fragilities in the system and overcome them by appropriate investments and implementation of a legal framework through which this can be achieved.

\section{Conclusion}

Most people live their entire existence without direct experience of major collective disasters. This shapes our perceptions as consumers and the features we seek in the products we purchase, which in turn guide the development and design of those products. But major public emergencies do happen and are in fact frequent worldwide (Lurie et al. 2013). Although mobile communication devices have already proven to be extraordinary aid tools in these situations (The Economist 2009a; BBC Media Action 2012; The Economist 2007; West \& Valentini 2013; The Telegraph 2011; Chen 2010), much more can be done to minimize their fragilities and increase their effectiveness. We believe that such concerns should be taken into account by consumers, policy makers, designers and manufacturing companies.

The features that make a mobile phone commercially attractive to daily use are not necessarily incompatible with those that make it useful in case of emergencies. For example, the improvement of battery life and physical resistance are not only critical in collective emergencies, they may also eliminate daily nuisances. This may be particularly important in developing and low income settings, where over $80 \%$ of the world population lives. In such cases, features such as robustness and battery life are expected to be even more crucial (e.g., if access to electricity is costly or unreliable). For example, a study among Bangladeshi students found that battery life was more important in purchasing decisions than the presence of a camera, color display, sound performance, memory capacity, style and even price (Siddique et al. 2013).

Other features, including the introduction of distress radar emission signals or walk-talk capabilities, could nevertheless increase costs. In such cases, consumers can be informed on the potential uses of such features, so they can create the demand for the market to fulfill. 
The emerging field of Mobile Health ( $m$-Health) focuses predominantly on software and application development, but largely takes hardware specifications for granted. But improvement of key features can make a difference in critical contexts, as even simple voice or text communication is not possible when devices - or their supporting infrastructure - are impaired. Important features can be incorporated by policy or by educating consumers (hence manufacturing companies) on the specifications that can be helpful in emergency conditions. With few exceptions (such as ensuring that all devices can receive radio signals), we favor the market-based approach, as regulatory measures quite often can dampen competition and innovation, and may hamper what is perhaps the most useful feature of mobile phones in a disaster: their ubiquity and vast penetration.

Companies and individuals who made the mobile revolution possible are the embodiment of how technological innovation and creativity can speed up the achievement of well-being for billons of individuals. In fact, the widespread use of the technological wonders represented by mobile phones may prove to be one of the greatest allies in the management of natural disasters, public health emergencies and humanitarian crises. Part of this extraordinary potential has already been achieved in currently available devices. However, even more would be possible if we can ensure robust communication for all those trapped in all too common "unthinkable" situations.

\section{Competing interests}

The authors have no financial competing interests to declare. Dr. Ghassem Asrar currently serves as Editor-in-Chief to Earth Perspectives.

\section{Author contributions}

WJA conceived the essay and wrote the first draft. WJA, CSP and GRA contributed to the writing and with ideas, revised and approved the final version.

\section{Acknowledgments}

We thank Lewis Kim, Ellis McKenzie, Bing Kung, Eduardo Beltrame and Alicia A. Levinsky (National Institutes of Health Library) for their valuable comments on manuscript. This research has been made possible by the support of the Fogarty International Center, National Institutes of Health.

Responsible editor: Thomas Krafft.

\section{Author details}

${ }^{1}$ Fogarty International Center, National Institutes of Health $(\mathrm{NIH}), 16$ Center Drive, Building 16, 20892 Bethesda, MD, USA. ${ }^{2}$ Origem Scientifica, Sao Paulo, Brazil. ${ }^{3}$ Joint Global Change Research Institute, Pacific Northwest National Laboratory, University of Maryland, Maryland, MD, USA.

Received: 26 February 2014 Accepted: 15 June 2014 Published: 4 July 2014

\section{References}

Allen E (2012) First an Electricity Blackout and now Cell Phone Coverage is Down as Users in Manhattan Battle Signal Failures. Mail Online, accessed Nov 4, 2013 at http://www.dailymail.co.uk/news/article-2225217/Superstorm-SandyNew-York-CELL-PHONE-coverage-users-battle-signal-failures.html
Australian Broadcast Corporation ABC (2010) Mobile invention could be desert lifeline. ABC, accessed Nov 4, 2013 at http://www.abc.net.au/science/articles/ 2010/07/12/2951206.htm\#.Ucxwlz7wKrh

Baze A (2012) Personal Emergency Communications: Staying in Touch PostDisaster: Technology, Gear and Planning. Max Publications.

BBC (2013) Mobile phone hits 40th birthday. BBC, accessed Nov 4, 2013 at http:// www.bbc.co.uk/news/technology-22013228

BBC Media Action (2012) Still left in the dark? How people in emergencies use communication to survive - and how humanitarian agencies can help. BBC Media Action, accessed Nov 4, 2013 at http://downloads.bbc.co.uk/mediaaction/ policybriefing/bbc_media_action_still_left_in_the_dark_policy_briefing.pdf

Bengtsson L, Lu X, Thorson A, Garfield R, von Schreeb J (2011) Improved response to disasters and outbreaks by tracking population movements with mobile phone network data: a post-earthquake geospatial study in Haiti. PLoS Med 8:e1001083

Chen BX (2010) Man Buried in Haiti Rubble Uses Iphone to Treat Wounds. Wired. com Gadget Lab, accessed Nov 4, 2013 at http://www.wired.com/gadgetlab/ 2010/01/haiti-survivor-iphone/

CNET (2013) Rugged phones posts on CNET. CNET, accessed Nov 4, 2013 at http://news.cnet.com/8300-5_3-0.html?keyword=rugged+phones

Covello VT, Hyer RN (2007) Effective Media Communication During Public Health Emergencies. A WHO Handbook. World Health Organization, Geneva, accessed Nov 4 at http://www.who.int/csr/resources/publications/WHO\% 20MEDIA\%20HANDBOOK.pdf?ua=1

Daily Mail Reporter (2011) "I"m not going to give up': Woman's last message to rescuers from beneath Christchurch earthquake rubble before her mobile phone battery runs out. Mail Online, accessed Nov 4, 2013 at http://www. dailymail.co.uk/news/article-1359354/New-Zealand-earthquake-A-mothersmessage-beneath-Christchurch-rubble.html

Effros M, Goldsmith A, Médard M (2010) The rise of instant wireless networks. Sci Am 302:72-77

Fuse A (2011) Medical relief activities conducted by Nippon medical school in the acute phase of the great east Japan earthquake. J Nippon Med Sch 78:397-400

Guha-Sapir D, Santos I, Borde A (2013) The Economic Impacts of Natural Disasters. Oxford University Press, Oxford; New York

Guo Y, Su XM (2012) Mobile device-based reporting system for Sichuan earthquake-affected areas infectious disease reporting in China. Biomed Environ Sci 25:724-729

Kenett DY, Portugali J (2012) Population movement under extreme events. PNAS 109:11472-11473

Lester R, Karanja S (2008) Mobile phones: exceptional tools for HIV/AIDS, health, and crisis management. Lancet Inf Dis 8:738-739

Lurie N, Manolio T, Patterson AP, Collins F, Frieden T (2013) Research as a part of public health emergency response. N England J Med 368:1251-1255

Murray MJ (2010) Communicating during a disaster. Anesth Analg 110:657-658

Napolitano D (2009) Getting the Message. Occup Health Safety 78:28-29

National Association Broadcasters (NAB) (2013) Equipping mobile phones with broadcast radio capability for emergency preparedness. NAB, accessed Nov 4, 2013 at http://www.nab.org/advocacy/issue.asp?id=2354\&issueid=1082

Neild B (2013) Smartphone Power StrugglesWill we Ever Have Battery-Free Mobiles? CNN, accessed Nov 4, 2013 at http://www.cnn.com/2013/02/27/ tech/battery-free-mobile-phones/index.html

Palen L, Liu SB (2007) Conference on Human Factors in Computing Systems. In Proceedings of the SIGCHI, New York, NY, pp 727-736

Patricelli F, Beakley JE, Carnevale A, Tarabochia M, Von Lubitz DKJE (2009) Disaster management and mitigation: the telecommunications infrastructure. Disasters 33:23-37

Quadir I (2005) Mobiles Fight Poverty | Video on TED.com. accessed Nov 4, 2013 at http://www.ted.com/talks/iqbal_quadir_says_mobiles_fight_poverty.html

Siddique ZR, Jamil AA, Ali B (2013) Product features affecting buying decision for mobile phone handset: a study on tertiary students segment in Bangladesh. Eur J Bus Manag 5:139-146

Srivastava M, Abdelzaher T, Szymanski B (2012) Human-centric sensing. Philos Transact A Math Phys Eng Sci 370:176-197

Stout KL, Neild B (2013) Launch of Nokia's \$20 Phone Begs Question: Is one Mobile Enough? CNN,accessed Nov 4, 2013 at http://www.cnn.com/2013/02/ 25/tech/nokia-budget-phone-elop/index.html

The Economist (2007) Dealing with disasters: Flood, famine and mobile phones. The Economist, Accessed Nov 4, 2013 at http://www.economist.com/node/ 9546242 
The Economist (2009a) Eureka moments. accessed Nov 4, 2013 at http://www. economist.com/node/14483872

The Economist (2009b) Mobile marvels. accessed Nov 4, 2013 at http://www. economist.com/node/14483896

The Economist (2012) Success and failure after the storm. The Economist, accessed Nov 4, 2013 at http://www.economist.com/blogs/schumpeter/ 2012/11/sandy

The Telegraph (2011) Turkey earthquake: Four pulled alive from rubble after victim calls for help on mobileTelegraph.co.uk. Accessed Nov 4, 2013 at http://www.telegraph.co.uk/news/worldnews/europe/turkey/8846337/Turkeyearthquake-Four-pulled-alive-from-rubble-after-victim-calls-for-help-onmobile.html

The World Bank (2012) Information and Communications for Development 2012. Maximizing Mobile. The World Bank, Washington, DC, accessed Nov 4, 2013 at http://www.worldbank.org/ict//C4D2012

Townsend AM, Moss ML (2005) Telecommunication infrastructure in disasters: preparing cities for crisis communication. accessed Nov 4, 2013 at http:// www.nyu.edu/ccpr/pubs/NYU-DisasterCommunications1-Final.pdf

West DM, Valentini E (2013) How Mobile Devices are Transforming Disaster Relief and Public Safety. Brookings Institution, Washington DC, accessed Nov 4, 2013 at http://www.brookings.edu/research/papers/2013/07/16-mobiletechnology-disaster-relief-west

Xia Y (2011) Mobile Communication. In: Katz J (ed) Dimensions of Social Policy. Transaction Publishers, NJ, pp 87-102

Yang C, Yang J, Luo X, Gong P (2009) Use of mobile phones in an emergency reporting system for infectious disease surveillance after the Sichuan earthquake in China. Bull World Health Org 87:619-623

Zhou A, Shi L, Mao Y, Tang J, Zeng Y (2012) Diffusion of new technology, health services and information after a crisis: a focus group study of the Sichuan "5.12" earthquake. Int J Health Plann Manage doi:10.1002/hpm.2137

Zook M, Graham M, Shelton T, Gorman S (2010) Volunteered geographic information and crowdsourcing disaster relief: a case study of the Haitian earthquake. World Medical Health Pol 2:7-33

doi:10.1186/2194-6434-1-24

Cite this article as: Alonso et al: Global health and natural disaster alerts: preparing mobile phones to endure the unthinkable. Earth Perspectives 2014 1:24.

\section{Submit your manuscript to a SpringerOpen ${ }^{\circ}$ journal and benefit from:}

- Convenient online submission

- Rigorous peer review

- Immediate publication on acceptance

- Open access: articles freely available online

- High visibility within the field

- Retaining the copyright to your article

Submit your next manuscript at $\gg$ springeropen.com 